\title{
A Educação a Distância na UEPG: o caso do Curso de Letras
}

\section{Distance education at UEPG: the case of Letras course}

Silvana Oliveira*

Universidade Estadual de Ponta Grossa

\section{Marly Catarina Soares** \\ Universidade Estadual de Ponta Grossa}

Resumo: Este artigo apresenta o panorama da oferta de vagas para o Curso de Letras - Português/Espanhol, na modalidade a distância, pela Universidade Estadual de Ponta Grossa, no período compreendido entre 2009 e 2013. Tal panorama tem em vista apresentar e refletir brevemente sobre as condições em que se deu o processo de implantação, consolidação e sustentação do Curso, bem como discutir os desafios enfrentados pelos agentes envolvidos em cada uma dessas etapas. A apresentação e a reflexão sobre o processo pelo qual passa a UEPG na oferta de vagas para o Curso de Letras - Português/Espanhol, na modalidade a distância, deve, prioritariamente, oportunizar que se vislumbre um quadro preliminar de ações conjuntas com vistas ao aprimoramento do Curso e à otimização do material impresso e tecnológico produzido ao longo desses 5 (cinco) anos no âmbito desta oferta.

Palavras-chave: Educação a distância - Ensino Superior - Letras.

Abstract: This work presents the scenery of vacancy offers for the Letras course - Portuguese/Spanish as distance education by Ponta Grossa State University (UEPG) in the period between 2009 and 2013. Such scenery aims to present and to consider briefly the conditions through which the process of implementation, consolidation and sustenance of the course has taken place. Besides, it aims to discuss the challenges faced by the agents involved in each one of the stages. The presentation and the consideration on the process through which UEPG goes in relation to the vacancies offer must primarily favor the glimpse of a preliminary chart of cooperative actions aiming the improvement of the course and the optimization of the written and technological materials produced throughout the five-year period of vacancy offers.

Keywords: distance education; higher education; Letras.

\section{Introdução}

A Universidade Estadual de Ponta Grossa participou, em 2005, do Edital CAPES n. 1, de 16 de dezembro de 2005, aberto para a seleção de Polos Municipais de Apoio Presencial e de Cursos Superiores de
* Doutora em Teoria e História Literária pela Unicamp. E-mail: $<$ coordt.let.silvana@ nutead.org>

** Doutora em Literatura pela Universidade Federal de Santa Catarina. E-mail: <coordc.let. marly@nutead.org > 
Instituições Federais de Ensino Superior na modalidade de Educação a Distância para o "Sistema Universidade Aberta do Brasil - UAB”. Tendo sido contemplada pelo Edital, a Instituição obteve autorização para a oferta de vagas nos Cursos de Licenciatura em Letras, História, Geografia, Pedagogia, Matemática e Educação Física, na modalidade a distância.

Para a participação da Instituição no Edital houve uma mobilização significativa do corpo docente das várias áreas interessadas na oferta de Cursos a Distância, uma vez que o Edital exigiu, a priori, a descrição dos cursos que poderiam ser ofertados; a apresentação de projeto pedagógico (com todos os componentes curriculares, ementários e detalhamento sobre a concepção pedagógica dos cursos propostos); indicativo de vagas; cronograma de execução, com a previsão de todas as etapas de aprovação interna na instituição de ensino, bem como os prazos de sua implementação. No que tange aos aspectos externos das ofertas, as propostas apresentadas ao Edital deveriam, também, indicar o número de polos de apoio presencial vinculados a cada curso e sua localização; descrição das necessidades específicas relativas aos polos de apoio presencial, de forma a prever a infraestrutura necessária e a logística para o recebimento, nestes polos, dos alunos aprovados para ingresso nos respectivos cursos. Em relação aos recursos humanos necessários à implantação das propostas, a Instituição indicou antecipadamente o corpo docente específico para a Educação a Distância, atendendo ao “desenho” elaborado pela CAPES, com os seguintes agentes no ensino:

a) Coordenador de Curso na modalidade EAD (responsável pela articulação pedagógica do Curso, bem como gerenciamento das questões administrativas);

b) Coordenador de Tutoria (responsável pela articulação do grupo de tutores a distância e presenciais em atuação no Curso);

c) Coordenador de Polo de apoio presencial (responsável pela coordenação do espaço físico destinado a receber os alunos presencialmente);

d) Professor-autor (responsável pela elaboração do material didático impresso, o que no caso da UEPG, configurou-se como Livro da Disciplina);

e) Professor-formador (responsável por propor forma e conteúdo para o Ambiente Virtual de Aprendizagem - AVA), que, no caso da UEPG, foi disponibilizado na Plataforma MOODLE;

f) Tutor a distância (responsável pelo atendimento, no AVA, aos alunos em cada uma das disciplinas do Curso, com foco na discussão dos conteúdos e fechamento das avaliações); 
g) Tutor presencial por curso (responsável por dar assistência aos alunos nos Polos de apoio presencial, no que tange a questões técnicas - informática e internet - e questões administrativas relacionadas à vida acadêmica do aluno).

Além do aspecto pedagógico, as propostas submetidas ao Edital Capes detalharam o orçamento estimado e o cronograma de desembolso das verbas a serem atribuídas. Sobre isso, vale esclarecer que o corpo docente indicado previamente para atuar na Educação a Distância, mediante aprovação no Edital, foi contemplado com bolsas CAPES, da modalidade Pesquisador I (para professores com experiência acima de 3 anos no ensino superior) e bolsas CAPES, na modalidade Pesquisador II (para professores com experiência acima de 1 ano no ensino superior) durante o período de atuação nos respectivos cursos. Os Coordenadores e tutores também foram contemplados com bolsas de acordo com as funções desempenhadas. Com a aprovação no Edital, a Instituição reestruturou o Núcleo de Tecnologia e Educação Aberta e a Distância da UEPG (NUTEAD), criado mediante decisão do Conselho de Ensino, Pesquisa e Extensão em 8/8/2002) para dar suporte técnico e administrativo para as ações pedagógicas pertinentes aos Colegiados e Coordenações de Curso.

\section{O Curso de Letras na modalidade a distância na UEPG}

Com a aprovação da UEPG no Edital 1 da Capes para Educação a Distância, a Instituição assumiu o compromisso de sustentar, dentro do Programa Universidade Aberta do Brasil, a oferta de vagas em 3 (três) entradas, no período de vigência do convênio coberto pelo Edital. As primeiras vagas para o Curso de Letras - Português/Espanhol, na modalidade a distância, foram disponibilizadas, mediante vestibular, no segundo semestre de 2008, tendo o curso iniciado em março de 2009.

Neste primeiro vestibular para o Curso de Letras - Português/Espanhol, na modalidade a distância, foram ofertadas 500 vagas, distribuídas em 10 Polos de apoio presencial nos municípios de Ponta Grossa, Colombo, Umuarama, Flor da Serra do Sul, Goioerê, Apucarana, Faxinal, Sarandi, Jacarezinho e Bandeirantes, do total de vagas ofertado, 309 foram preenchidas. Das 50 vagas ofertadas por Polo, 50\% destinaram-se, em atendimento a determinação da Capes, a professores da Educação Básica, atuantes na rede pública, em âmbito municipal, estadual ou federal.

No segundo vestibular para o Curso de Letras - Português/Espanhol, na modalidade a distância, realizado no segundo semestre de 2010, com ingresso previsto para o primeiro semestre de 2011, foram ofertadas 350 vagas, distribuídas em 7 Polos de apoio presencial nos municípios de Palmeira, Telêmaco Borba, Laranjeiras do Sul, Pinhão, Congonhinhas, Ipiranga e Lapa. Das vagas ofertadas, 298 foram preenchidas. Assim como no 
primeiro vestibular, 50\% destinaram-se, em atendimento a determinação da Capes, a professores da Educação Básica, atuantes na rede pública, em âmbito municipal, estadual ou federal.

O terceiro vestibular para o Curso de Letras - Português/Espanhol, na modalidade a distância, será realizado em outubro de 2013, com ingresso previsto para março de 2014. Neste vestibular serão ofertadas 200, distribuídas em 4 Polos de apoio presencial nos municípios de Cerro Azul, Cruzeiro do Oeste, Siqueira Campos e Itambé. Da mesma forma que nos vestibulares anteriores, 50\% das vagas são destinadas a professores da Educação Básica, atuantes na rede pública.

O Projeto Pedagógico do Curso, em especial a grade curricular, foi implementado com base no que está em vigor na modalidade presencial, desde a última reforma curricular, 2005. Este aspecto tem representado, para todos os agentes da educação a distância no curso, um desafio permanente, uma vez que a simples transposição do currículo do Curso na modalidade presencial para o ensino a distância não é suficiente para as demandas específicas desta modalidade. Esta problemática foi enfrentada desde o primeiro semestre do curso, quando se decidiu, em parceria com os demais colegiados de outros Cursos implantados na mesma época, que a estrutura curricular do Curso de Letras - Português/Espanhol, na modalidade a distância, seria desenvolvida em regime semestral, diferentemente do que acontece na modalidade presencial, cujas disciplinas são anuais.

Já nesse momento, Coordenações e professores envolvidos com o Curso assumiram o compromisso de organizar e distribuir a oferta das disciplinas de modo a contemplar os conteúdos previstos em cada ementa, por meio dos Livros didáticos e AVAs respectivos das disciplinas, em calendário semestral. Começava, assim, o processo de diferenciação entre os currículos.

Para uma melhor visualização do processo de adequação curricular por que passou o Curso de Letras na modalidade a distância, considere-se o quadro 1 , à esquerda, com o rol de disciplinas ofertadas na modalidade presencial e o quadro 2, à direita, com o rol de disciplinas já adequado à modalidade a distância, em sua primeira configuração: 


\begin{tabular}{|c|c|c|c|c|}
\hline Modalidade Presencial $^{\mathrm{I}}$ & \begin{tabular}{|l|} 
Carga \\
Horária
\end{tabular} & Modalidade a Distância ${ }^{I I}$ & \begin{tabular}{|l|} 
Carga \\
Horária \\
\end{tabular} & Adequações realizadas \\
\hline \multicolumn{5}{|c|}{ DISCIPLINAS DE FORMAÇÃO BÁSICA GERAL } \\
\hline Psicologia da Educação & $68 \mathrm{~h}$ & Psicologia da Educação & $68 \mathrm{~h}$ & Mantida \\
\hline $\begin{array}{l}\text { Fundamentos } \\
\text { da Educação }\end{array}$ & $68 \mathrm{~h}$ & |------------------------ & & Suprimida \\
\hline $\begin{array}{l}\text { Estrutura e } \\
\text { Funcionamento } \\
\text { da Educação Básica }\end{array}$ & $68 \mathrm{~h}$ & $\begin{array}{l}\text { Estrutura e Funcionamento } \\
\text { da Educação Básica }\end{array}$ & $68 \mathrm{~h}$ & Mantida \\
\hline $\begin{array}{l}\text { Fundamentos da } \\
\text { Língua Latina }\end{array}$ & $68 \mathrm{~h}$ & |------------------------ & & Suprimida \\
\hline $\begin{array}{l}\text { Introdução aos Estudos } \\
\text { Linguísticos: Fonética } \\
\text { Fonologia }\end{array}$ & $68 \mathrm{~h}$ & Linguística I & $68 \mathrm{~h}$ & $\begin{array}{l}\text { Readequação do nome } \\
\text { da disciplina e manutenção } \\
\text { da ementa }\end{array}$ \\
\hline \multirow{2}{*}{ Língua e Texto } & \multirow[t]{2}{*}{136} & Língua Portuguesa I & $68 \mathrm{~h}$ & \multirow{2}{*}{$\begin{array}{l}\text { Readequação de disciplina } \\
\text { anual para oferta semestral - } \\
\text { divisão da carga horária }\end{array}$} \\
\hline & & Língua Portuguesa II & $68 \mathrm{~h}$ & \\
\hline \multirow{2}{*}{ Diacronia do Português } & \multirow[t]{2}{*}{$68 \mathrm{~h}$} & História da Língua Portuguesa I & $68 \mathrm{~h}$ & \multirow{2}{*}{$\begin{array}{l}\text { Aumento da Carga horária e } \\
\text { renomeação da disciplina }\end{array}$} \\
\hline & & História da Língua Portuguesa II & $68 \mathrm{~h}$ & \\
\hline \multirow{2}{*}{$\begin{array}{l}\text { Morfossintaxe } \\
\text { do Português }\end{array}$} & \multirow[t]{2}{*}{136} & Língua Portuguesa III & $68 \mathrm{~h}$ & \multirow{2}{*}{$\begin{array}{l}\text { Readequação de disciplina } \\
\text { anual para oferta semestral - } \\
\text { divisão da carga horária }\end{array}$} \\
\hline & & Língua Portuguesa IV & $68 \mathrm{~h}$ & \\
\hline Teoria Literária I & $68 \mathrm{~h}$ & Teoria Literária I & $68 \mathrm{~h}$ & Mantida \\
\hline Teoria Literária II & $68 \mathrm{~h}$ & Teoria Literária II & $68 \mathrm{~h}$ & Mantida \\
\hline $\begin{array}{l}\text { Tópicos de Lingüística } \\
\text { Aplicada }\end{array}$ & $68 \mathrm{~h}$ & Linguística II & $68 \mathrm{~h}$ & Renomeação da disciplina \\
\hline Literatura Brasileira I & $68 \mathrm{~h}$ & Literatura Brasileira I & $68 \mathrm{~h}$ & Mantida \\
\hline Literatura Brasileira II & $68 \mathrm{~h}$ & Literatura Brasileira II & $68 \mathrm{~h}$ & Mantida \\
\hline Literatura Brasileira III & $68 \mathrm{~h}$ & Literatura Brasileira III & $68 \mathrm{~h}$ & Mantida \\
\hline Literatura Portuguesa I & $68 \mathrm{~h}$ & Literatura Portuguesa I & $68 \mathrm{~h}$ & Mantida \\
\hline Literatura Portuguesa II & $68 \mathrm{~h}$ & Literatura Portuguesa II & $68 \mathrm{~h}$ & Mantida \\
\hline \multirow{2}{*}{ Texto e Discurso } & \multirow[t]{2}{*}{68} & Língua Portuguesa V & $68 \mathrm{~h}$ & \multirow{2}{*}{$\begin{array}{l}\text { Aumento da Carga horária e } \\
\text { renomeação da disciplina }\end{array}$} \\
\hline & & Língua Portuguesa VI & $68 \mathrm{~h}$ & \\
\hline \multirow{2}{*}{ Semântica e Estilística } & \multirow[t]{2}{*}{51} & Língua Portuguesa VII & $68 \mathrm{~h}$ & \multirow{2}{*}{$\begin{array}{l}\text { Aumento da Carga horária e } \\
\text { renomeação da disciplina }\end{array}$} \\
\hline & & Língua Portuguesa VIII & $68 \mathrm{~h}$ & \\
\hline $\begin{array}{l}\text { Língua Brasileira de } \\
\text { Sinais - LIBRAS } \\
\end{array}$ & $51 \mathrm{~h}$ & Língua Brasileira de Sinais - LIBRAS & $51 \mathrm{~h}$ & Mantida \\
\hline \multicolumn{5}{|c|}{ DISCIPLINAS DE PRÁTICA COMO COMPONENTE CURRICULAR } \\
\hline \multirow{2}{*}{$\begin{array}{l}\text { Prática I - Leitura e } \\
\text { Produção de Texto }\end{array}$} & \multirow[t]{2}{*}{136} & Prática de Ensino I & 68 & \multirow{2}{*}{$\begin{array}{l}\text { Readequação de disciplina } \\
\text { anual para oferta semestral - } \\
\text { divisão da carga horária }\end{array}$} \\
\hline & & Prática de Ensino II & 68 & \\
\hline Prática II - Cultura Oral & 136 & Prática de Ensino III & 68 & $\begin{array}{l}\text { Readequação de disciplina } \\
\text { anual para oferta semestral - } \\
\text { redução da carga horária }\end{array}$ \\
\hline \multirow{2}{*}{$\begin{array}{l}506124 \text { Prática III - } \\
\text { Literatura }\end{array}$} & \multirow[t]{2}{*}{68} & Prática de Ensino IV & $68 \mathrm{~h}$ & \multirow{2}{*}{$\begin{array}{l}\text { Readequação de disciplina } \\
\text { anual para oferta semestral - } \\
\text { aumento da carga horária }\end{array}$} \\
\hline & & Prática de Ensino V & $68 \mathrm{~h}$ & \\
\hline
\end{tabular}


continuação

\begin{tabular}{|c|c|c|c|c|}
\hline Modalidade Presencial $^{\mathrm{I}}$ & \begin{tabular}{|l|} 
Carga \\
Horária \\
\end{tabular} & Modalidade a Distância ${ }^{\mathrm{II}}$ & \begin{tabular}{|l|} 
Carga \\
Horária \\
\end{tabular} & Adequações realizadas \\
\hline $\begin{array}{l}\text { Prática IV - } \\
\text { Comunicação }\end{array}$ & $68 \mathrm{~h}$ & Prática de ensino VI & $68 \mathrm{~h}$ & Mantida \\
\hline Didática & $68 \mathrm{~h}$ & Didática & $68 \mathrm{~h}$ & Mantida \\
\hline \multicolumn{5}{|c|}{ DISCIPLINAS DE FORMAÇÃO ESPECÍFICA PROFISSIONAL } \\
\hline \multirow{2}{*}{ Língua Espanhola I } & \multirow[t]{2}{*}{$136 h$} & Língua Espanhola I & $68 \mathrm{~h}$ & \multirow{2}{*}{$\begin{array}{l}\text { Readequação de disciplina } \\
\text { anual para oferta semestral - } \\
\text { divisão da carga horária }\end{array}$} \\
\hline & & Língua Espanhola I I & $68 \mathrm{~h}$ & \\
\hline \multirow{2}{*}{ Língua Espanhola II } & \multirow[t]{2}{*}{$136 \mathrm{~h}$} & Língua Espanhola III & $68 \mathrm{~h}$ & \multirow{2}{*}{$\begin{array}{l}\text { Readequação de disciplina } \\
\text { anual para oferta semestral - } \\
\text { divisão da carga horária }\end{array}$} \\
\hline & & Língua Espanhola IV & $68 \mathrm{~h}$ & \\
\hline \multirow{2}{*}{ Língua Espanhola III } & \multirow[t]{2}{*}{$136 h$} & Língua Espanhola V & $68 \mathrm{~h}$ & \multirow{2}{*}{$\begin{array}{l}\text { Readequação de disciplina } \\
\text { anual para oferta semestral - } \\
\text { divisão da carga horária }\end{array}$} \\
\hline & & Língua Espanhola VI & $68 \mathrm{~h}$ & \\
\hline \multirow{2}{*}{ Língua Espanhola IV } & \multirow[t]{2}{*}{$136 h$} & Língua Espanhola VII & $68 \mathrm{~h}$ & \multirow{2}{*}{$\begin{array}{l}\text { Readequação de disciplina } \\
\text { anual para oferta semestral - } \\
\text { divisão da carga horária }\end{array}$} \\
\hline & & Língua Espanhola VIII & $68 \mathrm{~h}$ & \\
\hline \multirow{2}{*}{ Literatura Espanhola } & \multirow[t]{2}{*}{$68 \mathrm{~h}$} & Literatura Espanhola I & $68 \mathrm{~h}$ & \multirow{2}{*}{$\begin{array}{l}\text { Mantida com aumento da } \\
\text { Carga horária }\end{array}$} \\
\hline & & Literatura Espanhola II & $68 \mathrm{~h}$ & \\
\hline \multirow{2}{*}{$\begin{array}{l}\text { Literatura } \\
\text { Hispano-americana }\end{array}$} & \multirow[t]{2}{*}{$68 \mathrm{~h}$} & Literatura Hispano-americana I & $68 \mathrm{~h}$ & \multirow{2}{*}{$\begin{array}{l}\text { Mantida com aumento da } \\
\text { Carga horária }\end{array}$} \\
\hline & & Literatura Hispano-americana II & $68 \mathrm{~h}$ & \\
\hline \multirow{2}{*}{$\begin{array}{l}\text { Orientação de Trabalho } \\
\text { de Conclusão de Curso }\end{array}$} & \multirow[t]{2}{*}{34} & $\begin{array}{l}\text { Orientação de Trabalho de Conclusão de } \\
\text { Curso I }\end{array}$ & 34 & \multirow{2}{*}{$\begin{array}{l}\text { Mantida com aumento da } \\
\text { Carga horária }\end{array}$} \\
\hline & & $\begin{array}{l}\text { Orientação de Trabalho de Conclusão de } \\
\text { Curso II }\end{array}$ & 34 & \\
\hline \multicolumn{5}{|c|}{ DISCIPLINAS DE ESTÁGIO SUPERVISIONADO } \\
\hline \multirow{2}{*}{$\begin{array}{l}\text { Estágio Curricular } \\
\text { Supervisionado em } \\
\text { Língua Portuguesa e } \\
\text { Literatura }\end{array}$} & \multirow[t]{2}{*}{204} & $\begin{array}{l}\text { Estágio Curricular Supervisionado em } \\
\text { Língua Portuguesa e Literatura I }\end{array}$ & 102 & \multirow{2}{*}{$\begin{array}{l}\text { Readequação de disciplina } \\
\text { anual para oferta semestral - } \\
\text { divisão da carga horária }\end{array}$} \\
\hline & & \begin{tabular}{|l} 
Estágio Curricular Supervisionado em \\
Língua Portuguesa e Literatura II \\
\end{tabular} & 102 & \\
\hline \multirow{2}{*}{$\begin{array}{l}503194 \text { Estágio } \\
\text { Curricular Supervisionado } \\
\text { em Língua Espanhola }\end{array}$} & \multirow[t]{2}{*}{204} & $\begin{array}{l}\text { 503194 Estágio Curricular Supervisionado } \\
\text { em Língua Espanhola I }\end{array}$ & 102 & \multirow{2}{*}{$\begin{array}{l}\text { Readequação de disciplina } \\
\text { anual para oferta semestral - } \\
\text { divisão da carga horária }\end{array}$} \\
\hline & & $\begin{array}{l}\begin{array}{l}\text { 503194 Estágio Curricular Supervisionado } \\
\text { em Língua Espanhola II }\end{array} \\
\end{array}$ & 102 & \\
\hline \multicolumn{5}{|c|}{ DISCIPLINAS DE DIVERSIFICAÇÃO OU APROFUNDAMENTO } \\
\hline $\begin{array}{l}\text { Conversação em Língua } \\
\text { Espanhola }\end{array}$ & $68 \mathrm{~h}$ & Conversação em Língua Espanhola & $68 \mathrm{~h}$ & Mantida \\
\hline Língua Alemã & $68 \mathrm{~h}$ & 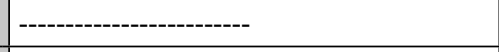 & & Suprimida \\
\hline Literatura e Cinema & $68 \mathrm{~h}$ & Literatura e Cinema & $68 \mathrm{~h}$ & Mantida \\
\hline $\begin{array}{l}\text { Tópicos de Civilização } \\
\text { Francesa }\end{array}$ & $68 \mathrm{~h}$ & 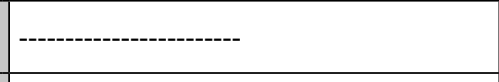 & & Suprimida \\
\hline Crítica Literária & $68 \mathrm{~h}$ & --------------------------- & & Suprimida \\
\hline Gramática Normativa & $68 \mathrm{~h}$ & Oficina de Leitura e Produção de Texto & $68 \mathrm{~h}$ & Readequada \\
\hline Língua Portuguesa & $68 \mathrm{~h}$ & - & & Suprimida \\
\hline Literatura e Mulher & $68 \mathrm{~h}$ & Iniciação à Leitura Literária & $68 \mathrm{~h}$ & Readequada \\
\hline
\end{tabular}


conclusão

\begin{tabular}{|l|l|l|l|l|}
\hline Modalidade Presencial $^{\text {I }}$ & $\begin{array}{l}\text { Carga } \\
\text { Horária }\end{array}$ & Modalidade a Distância ${ }^{\text {II }}$ & $\begin{array}{l}\text { Carga } \\
\text { Horária }\end{array}$ & Adequações realizadas \\
\hline $\begin{array}{l}\text { Seminários Temáticos } \\
\text { sobre a Realidade } \\
\text { Escolar Brasileira }\end{array}$ & $68 \mathrm{~h}$ & $\begin{array}{l}\text { Teorias da Leitura e Formação do } \\
\text { leitor - Atividade Complementar }\end{array}$ & $68 \mathrm{~h}$ & Readequada \\
\hline $\begin{array}{l}\text { Textualidades } \\
\text { Contemporâneas }\end{array}$ & $68 \mathrm{~h}$ & Textualidades Contemporâneas & $68 \mathrm{~h}$ & Mantida \\
\hline
\end{tabular}

${ }^{\text {I }}$ Curso de Licenciatura em Letras Português/Espanhol e Respectivas Literaturas (vespertino e noturno) Reconhecido pelo Decreto Est. n. ${ }^{\circ}$ 3.752, de 20.03.01, publicado no DOE $n^{\circ} 5.950$ de 21.03.01. Renovação de Reconhecimento Decreto $n^{\circ}$. 8404, de 22.09.10. DOE. $\mathrm{n}^{\circ} 8.309$ de 22.09.10, conforme publicado no catálogo Instituicional, disponível em http://www.uepg.br/ catalogo/, consultado em 14/08/2013.

II Curso de Licenciatura em Letras Português/Espanhol e Respectivas Literaturas - UAB (integral), Currículo 1, Autorizado pela Resolução CEPE n. ${ }^{\circ} 227$ de 16.12.08, disponível em http://www.uepg.br/catalogo/, consultado em 14/08/2013.

A grade do primeiro semestre de todos os Cursos ofertados na modalidade a distância, incluindo o Curso de Letras, desde a primeira entrada em 2009, foi acrescida de duas disciplinas de fundamento técnico e metodológico, tendo em vista a formação específica necessária ao aluno em um curso na modalidade a distância. Nesta perspectiva, foram concebidas as disciplinas chamadas de Módulo Introdutório, com acesso apenas pelo AVA, e Introdução à Educação a Distância, ambas com carga horária de 68h, com acesso pelo AVA e também por meio do Livro da Disciplina.

No caso da primeira disciplina, Módulo Introdutório, a concepção dos conteúdos busca atender às necessidades iniciais do usuário de uma Plataforma de ensino em ambiente virtual. Já a Introdução à Educação a Distância apresenta ao aluno as informações básicas sobre a modalidade ensino a distância, de modo a que ele venha a compreender os meios de realização do Curso em que está inserido. Esta disciplina se propõe, também, a refletir sobre a história, os avanços e potencialidades da Educação a Distância no Brasil e no mundo. Os conteúdos da disciplina foram sistematizados no livro Introdução à Educação a Distância (2010), produzido pelas professoras doutoras Cleide Aparecida Faria Rodrigues e Leide Mara Schmidt.

No âmbito específico da área de Letras, para o primeiro semestre do Curso, foram disponibilizadas de imediato as disciplinas de Oficina de Leitura e Produção de Textos e Iniciação à Leitura Literária. Estas disciplinas passaram a compor o rol de Disciplinas de Aprofundamento e Diversificação na Grade Curricular original do Curso. A decisão por implementar essas disciplinas já no primeiro semestre do Curso justificou-se pela compreensão de que o aluno da modalidade a distância necessitaria de um aprofundamento inicial em atividades de leitura e escrita, nos vários gêneros discursivos, de modo a habilitar-se suficientemente para as demandas de leitura e escrita que a dinâmica de um Curso a Distância, em ambiente virtual, apresenta desde os primeiros momentos de sua realização. 


\section{O alunado de letras UAB - UEPG}

A primeira turma do Curso de Letras Português/Espanhol - UAB se constituiu a partir do vestibular realizado em final de 2008, e a matrícula destes alunos realizou-se em fevereiro de 2009, com a definição de dez turmas, locadas em dez polos, todos em diferentes regiões do Paraná. O quadro abaixo discrimina os polos e o número de alunos matriculados em cada um:

\begin{tabular}{|c|c|}
\hline POLO & Número de alunos \\
\hline Apucarana & 39 \\
\hline Bandeirantes & 28 \\
\hline Colombo & 40 \\
\hline Faxinal & 23 \\
\hline Flor da Serra do Sul & 48 \\
\hline Goioerê & 35 \\
\hline Jacarezinho & 30 \\
\hline Ponta Grossa & 40 \\
\hline Sarandi & 09 \\
\hline Umuarama & 17 \\
\hline
\end{tabular}

Fonte - PROGRAD - UEPG - Seção de Matrícula - 2009

Durante os quatro anos - oito semestres - de duração desta primeira oferta, vários fatores - entre pessoais, profissionais e até de compreensão da dinâmica do curso a distância, especificamente o oferecido pela UEPG - concorreram para que o número de alunos sofresse diminuição em cada um dos polos. Entretanto, nenhum polo deixou de funcionar por falta absoluta de aluno. Devido à dinâmica da configuração das turmas, é necessária a sua reorganização a cada semestre, para atender o estabelecido pelo convênio, que rege um tutor a cada vinte e cinco alunos. Assim, partindo de dez turmas em 2009, estas foram se configurando de tal forma que, no oitavo semestre, estabeleceram-se quatro turmas envolvendo alunos de dois a três polos em cada uma. Consequentemente, o número de tutores on line caiu de dezessete, no princípio de 2009, para oito no último semestre da primeira turma.

No início de 2013, tivemos as primeiras formaturas dos alunos ingressantes em 2009. Foram 90 alunos que participaram das solenidades de formatura que congregaram autoridades acadêmicas da Universidade Estadual de Ponta Grossa, além de autoridades dos municípios envolvidos, do Estado como um todo e até mesmo do governo federal. Embora tenham ocorrido as formaturas, o Curso de Letras, turma de 2009, possui um número considerável de alunos remanescentes que intencionam concluí-lo no ano corrente de 2013. 
A participação dos alunos no Curso EaD se dá em uma carga horária de 20 horas semanais on line, que pode ser gerenciada segundo as suas necessidades. Os contatos com professores e tutores ocorrem via plataforma MOODLE, além de webconferências, skype, email, e outras redes sociais disponíveis na internet. A plataforma MOODLE oferece várias ferramentas para a consolidação da comunicação entre aluno/tutor/professor, tais como fóruns, chat, webconferência... Durante o semestre, o aluno deve participar de atividades presenciais, que são as provas presenciais e seminários.

O acompanhamento das atividades na plataforma pela coordenação do curso mostrou como se constitui o perfil dos alunos que o frequentam. São, em sua maioria, alunos que já têm uma graduação, muitos estão atuando como professores, alguns vieram diretamente do ensino médio e outros frequentam paralelamente cursos de pós-graduação lato e stricto sensu.

De acordo com a avaliação realizada pela CPA - UEPG, em 2010, a faixa etária dos alunos apresenta grande variabilidade, com idades entre 19 e 53 anos, a maioria sendo do sexo feminino e casada. A avaliação revelou ainda que o Ensino Médio ocorreu em escolas públicas, com prevalência no ensino regular e profissionalizante. Os alunos participantes da avaliação indicaram a preferência pelo Ensino a distância pelo fato de ser possível conciliar o estudo com as suas atividades profissionais e ou pessoais (CPA, 2010, p. 11).

Com relação ao comportamento do alunado EaD, não há como definir um padrão entre eles, pois alguns alunos mantém um contato frequente com os tutores, buscando esclarecer suas dúvidas, resolvendo as tarefas e atividades em tempo hábil para a refacção, mas existem outros que não fazem questão dos feedbacks e deixam claro isso, postando suas obrigações no final do prazo para o fechamento da disciplina. As turmas são bastante heterogêneas, como se pode constatar pelo número de alunos que terminaram o curso no tempo regular e pelos que ficaram com pendências a serem cumpridas, especificamente os da turma de 2009.

\begin{tabular}{|c|c|c|}
\hline POLO & Formados 2012-2 & Em curso \\
\hline Apucarana & 06 & 04 \\
\hline Bandeirantes & 14 & 03 \\
\hline Colombo & 11 & 08 \\
\hline Faxinal & 06 & 02 \\
\hline Flor da Serra do Sul & 16 & 03 \\
\hline Goioerê & 10 & 05 \\
\hline Jacarezinho & 09 & 03 \\
\hline Ponta Grossa & 12 & 04 \\
\hline Sarandi & 01 & 02 \\
\hline Umuarama & 06 & 02 \\
\hline
\end{tabular}

Fonte - arquivos gerenciados pela coordenação com base em informações da PROGRAD-UEPG 
Em 2010, houve o segundo vestibular para Letras UaB constituindo assim a turma de 2011. Definiram-se sete turmas em sete pólos, contemplando cidades que não constavam na primeira turma (2009). As vagas ofertadas não foram preenchidas da mesma forma como ocorreu com a primeira turma.

\begin{tabular}{|c|c|}
\hline POLO & Número de alunos \\
\hline Congonhinhas & 40 \\
\hline Ipiranga & 44 \\
\hline Lapa & 40 \\
\hline Laranjeiras do Sul & 37 \\
\hline Palmeira & 42 \\
\hline Pinhão & 45 \\
\hline Telêmaco Borba & 50 \\
\hline
\end{tabular}

Fonte - PROGRAD - UEPG - Seção de Matrícula - 2011

Conforme se vê, ocorreu uma procura maior pelo Curso de Letras nesse vestibular, mas ainda assim não houve preenchimento das vagas, uma vez que foram ofertadas 50 em cada um dos polos. Nos dois primeiros semestres, manifestou-se um decréscimo no número de alunos proporcionado por razões diversas, desde a não adaptação à metodologia empregada a problemas pessoais. Na primeira turma, de 2009, percebeu-se uma evasão considerável no quinto semestre, quando da realização da disciplina do Estágio Curricular Supervisionado, o que não ocorreu com a turma em curso. A evasão se deu muito mais do primeiro para o segundo semestre, mantendo-se nos semestres seguintes o mesmo número de alunos com pequenas variações.

Uma das grandes questões nos cursos a distância, além dos esforços para o preenchimento das vagas, é a fidelização dos alunos para se conseguir o maior número de concluintes. Essa árdua tarefa envolve muitas pessoas, como coordenadores de polo, tutores presenciais, coordenador de curso, tutores on line, coordenador de tutoria. É uma batalha diária, corpo a corpo. Aos primeiros sinais de ausência do aluno na plataforma, o tutor on line imediatamente se vale dos diferentes recursos via plataforma MOODLE, assim como email institucional ou particular, para contatar o aluno, procurando trazê-lo de volta ao curso. Se esses primeiros esforços não obtiverem resultados positivos, são acionados os tutores presenciais, que, em alguns casos, recorrem a um contato mais pessoal, via telefone ou mesmo visitas à residência. Diferentemente do aluno presencial, o aluno da EaD é mais suscetível à desmotivação, e a menor dificuldade encontrada se torna motivo para a desistência. Neste momento, é muito importante a figura do tutor, que é quem mais se relaciona com os alunos. 


\section{Profissionais a serviço da EaD}

A característica principal do Curso de Letras UAB - UEPG é a não presença física das pessoas envolvidas no processo ensino-aprendizagem do aluno em, aproximadamente, $70 \%$ das atividades configuradas como assíncronas - quando o aluno e os outros atores do processo se mantêm conectados ao Ambiente Virtual de Aprendizagem em diferentes momentos - ou síncronas - quando o aluno e os outros atores do processo se mantêm conectados ao Ambiente Virtual de Aprendizagem simultaneamente, como nos chats, atividades de comunicação por áudio e webconferências. Sendo assim, os 30\% restantes do tempo previsto para integralização dos estudos na modalidade $\mathrm{EaD}$ são desenvolvidos por meio de atividades presenciais, na forma de Seminários de Estudo e Realização de Avaliações Presenciais. O contato viabilizado por meio do Ambiente Virtual de Aprendizagem se dá on line, conforme já colocado anteriormente, com a utilização das tecnologias que propiciam tais situações. Nessa dinâmica estabelecida, algumas figuras são de extrema importância para a viabilização do processo como um todo. Cada uma das pessoas envolvidas deve cumprir seu papel com precisão, o que nem sempre é fácil pela complexidade da rede de trabalho na qual cada uma dessas figuras deve atuar, desde o ambiente virtual de aprendizagem até a finalização dos processos de avaliação múltiplos pelos quais passa o aluno.

O curso de Letras UAB - UEPG mantém em seu quadro de apoio técnico-administrativo e docente a seguinte equipe de colaboradores ${ }^{1}$ :

Coordenador de Curso: é a pessoa responsável pela qualidade científica e didático-pedagógica do curso. Deve acompanhar o curso, tomando as medidas necessárias para implementar melhorias e adequá-lo às necessidades de mudanças apresentadas durante o seu desenvolvimento.

Coordenador de Tutoria: deve desenvolver ações de orientação, planejamento, acompanhamento e avaliação do trabalho dos tutores, que poderá ser realizado on line de forma síncrona ou assíncrona, via chats, fóruns, correio eletrônico ou presencialmente, nos seminários. Nos casos de impedimento do Coordenador de Curso, o Coordenador de Tutoria deve substituí-lo, por não haver no formato da UAB a figura do vice-coordenador de Curso.

Coordenador de estágio: é responsável pela orientação do projeto de estágio, bem como pelo seu acompanhamento e avaliação. Esta coordenação atua conjuntamente com os tutores presenciais que, por sua vez, articulam-se com as equipes das escolas para a realização dos estágios e da avaliação do desempenho dos estagiários.

Coordenador de polo presencial: executa tarefas organizacionais e administrativas no âmbito da unidade de ensino sob sua responsabilidade. Cabe-lhe supervisionar o trabalho dos Tutores e dos demais membros

${ }^{1}$ Os colaboradores e suas funções foram subtraídos do projeto pedagógico do Curso de Letras UAB UEPG, 2007-2013 
da equipe de apoio, manter contatos e enviar relatórios periódicos para o Coordenador do Curso, proceder análise administrativa e pedagógica do desempenho dos tutores, dos estudantes e dos demais membros da equipe de apoio, sugerindo medidas necessárias para corrigir possíveis desvios.

Docente pesquisador/autor: é o professor responsável pela produção do livro didático de sua disciplina conforme sua área de estudo. Deve ser titulado em nível de pós-graduação stricto sensu e ter experiência docente na área em que escreve, bem como na produção de materiais escritos na modalidade EaD. Orienta o Trabalho de Conclusão de Curso (TCC) e participa das bancas de defesa do TCC.

Docente pesquisador / formador: preferentemente deve ser o mesmo professor pesquisador que produziu o livro para a disciplina de sua responsabilidade. Sua titulação deve ser em nível de pós-graduação stricto sensu e ter experiência docente na área em que atua. Suas atividades frente ao curso são: mediar o processo educacional, planejar e ministrar as videoconferências, orientar a organização de seminários, produzir material didático audiovisual e material on line, orientar as atividades práticas do curso, planejar e corrigir as verificações de aprendizagem, com o intuito de identificar se os objetivos da disciplina estão sendo alcançados. Ainda dar feed back para o professor autor (caso não seja ele o autor) sobre a qualidade do material escrito, valendo-se dos depoimentos dos estudantes, e colaborar no acompanhamento/diagnóstico /avaliação do curso, com vistas a subsidiar o processo de construção do conhecimento. E, por fim, pode orientar o Trabalho de Conclusão de Curso (TCC) e participar das bancas de defesa.

Tutor on-line: é o que mais se envolve com o aluno, pois seu trabalho está diretamente relacionado a ele. Para que o contato se estabeleça de forma satisfatória, ele deve manter-se conectado com os estudantes, sanando suas dúvidas quanto ao conteúdo e desenvolvimento das disciplinas. Deve estimular e orientar constantemente os alunos, de modo a evitar desistências, evasão, ou atrasos em relação ao cronograma das disciplinas do curso. Deve ainda sugerir leituras complementares e outras atividades que auxiliem o aluno em seu processo de aprendizagem. Seu trabalho constitui ainda de acompanhar os grupos de estudantes em chats, fóruns e videoconferências e auxiliar o professor formador na produção de materiais complementares necessários ao curso e na correção das avaliações. O tutor on line é a figura que mantém contato frequente com a coordenação do curso, com os tutores presenciais e com os professores formadores. Além disso, podem apresentar sugestões que aperfeiçoem o desempenho dos estudantes, dar feedback sobre as atividades realizadas, para que estes se auto-avaliem em relação aos objetivos previstos. Podem ainda colaborar no acompanhamento/diagnóstico /avaliação do curso, para subsidiar o processo de construção do conhecimento. 
Tutor presencial: é o orientador acadêmico com formação superior adequada que será responsável pelos estudantes nos polos municipais de apoio presencial. O papel dos tutores é acompanhar o desenvolvimento de todo o processo de ensino aprendizagem, fazer a mediação entre estudantes e docentes, orientar as atividades dos estudantes para a superação de suas dificuldades, planejar e participar de chats e fóruns, fornecer informações que subsidiem o trabalho da coordenação do curso e dos docentes, diagnosticando e verificando o desenvolvimento das competências. Coordena estudos e debates entre os cursistas, nas diferentes disciplinas, a partir das videoconferências, do material escrito e das atividades propostas. Também auxilia no planejamento, supervisão e avaliação das práticas de ensino e do estágio supervisionado. A fim de identificar como os alunos estão evoluindo, os tutores utilizam várias técnicas e instrumentos, principalmente entrevistas, questionários, observações, portfólios. Por estarem em contato permanente com os estudantes, durante o decorrer do curso, os tutores são atores privilegiados no sentido de identificar se estes estão atingindo os objetivos propostos.

Secretária: responsabiliza-se pela correspondência, pelos e-mails, pelos malotes e pelas ligações telefônicas, envia fax, elabora ofícios e encaminha materiais para os polos. Mantém contato permanente com a coordenação dos polos presenciais, auxiliando-a nas dificuldades encontradas.

Além dessas pessoas, um contingente maior ainda trabalha nos bastidores para que cada etapa do processo educacional se efetive da melhor maneira possível. Seja na produção de material didático-pedagógico, na confecção dos livros, na diagramação da plataforma, no funcionamento adequado do complexo tecnológico, os técnicos, os profissionais gabaritados estão trabalhando em conjunto com a mesma disposição para o bem comum que é a formação dos alunos via on line, na plena utilização do ambiente virtual de aprendizagem.

\section{Considerações para o futuro do Curso de Letras na modalidade Ead na UEPG}

O desafio representado pela oferta do Curso de Letras Português/ Espanhol desde o ano de 2009 tem sido enfrentado com determinação e dinamismo pelo corpo docente da área na Instituição e por valorosos colaboradores convidados de outras instituições. É claro para todo o grupo, no entanto, que há aspectos a serem aperfeiçoados, tanto no que tange à institucionalização das atividades profissionais desenvolvidas no âmbito da EaD nesta Universidade quanto à inserção do aluno desta modalidade EaD em todas as instâncias de formação a que ele faz jus, como atividades formalizadas de pesquisa e extensão, participação efetiva nas atividades acadêmicas, científicas e culturais que a Universidade oferece a todo o seu 
corpo discente e a presença efetiva junto às entidades de representação estudantil na Instituição.

Com a compreensão de que o Curso de Letras Português/Espanhol na modalidade a distância representa uma resposta positiva à demanda por formação universitária no nosso país, todo o grupo hoje envolvido nesta oferta tem o compromisso renovado a cada semestre com a universidade pública, gratuita e de qualidade.

\section{Referências}

ALAVA, S. (Org.). Ciberespaço e formações abertas: rumo a novas práticas educacionais? Porto Alegre: Artmed, 2002.

ALVES, J. R. M. “A história da EAD no Brasil”. In: LITTO, F. M, FORMIGA, M. (orgs). In: Educação a distância: o estado da arte.São Paulo: Pearson Education do Brasil, 2009, p.09-13.

BELLONI, M. L. Educação a distância. Campinas: Autores Associados, 2001.

CASTELLS, M. A sociedade em rede. São Paulo: Paz e Terra, 1999.

CHAVES, E. Conceitos Básicos: educação a distância. EdutecNet: Rede de Tecnologia da Educação. Disponível em http://www.edutecnet.com.br. Acesso em 28/10/2008.

. C. Tecnologia na Educação, Ensino a Distância, e Aprendizagem Mediada pela Tecnologia: conceituação básica. Revista Educação. Faculdade de Educação da Pontifícia Universidade Católica de Campinas, Ano III, Número 7, Novembro de 1999.

EMERENCIANO, M. do S. J.; SOUSA, C. A.L. de; FREITAS, L. G. de. Ser Presença como Educador, Professor e Tutor. Colabor@ - Revista Digital da CVA - RICESU ISSN 1519-8529. V.1, n.1-p.4-11, Ago. 2001.

FLEMMING, D. M.; LUZ, E F.; LUZ, R. A.. Monitorias e tutorias: um trabalho cooperativo na educação a distância. Disponível em: <http:// www.abed.org.br/ publique/ . Acesso em: 02 abr. 2004.

LITWIN, E. (Org.). Educação a distância: temas para o debate de uma nova agenda educativa. Porto Alegre: Artmed, 2000.

LUCENA, C.; FUKS, H. A educação na era da internet. Rio de Janeiro: Clube do Futuro, 2000.

MARTINS, O. B. A educação superior a distância e a democratização do saber. Petrópolis, Vozes, 1991.

MATTAR, J. Interatividade e aprendizagem. In: LITTO, F.M, FORMIGA, M. (orgs). In: Educação a distância: o estado da arte.São Paulo: Pearson Education do Brasil, 2009, p.112-120. 
ROCHA, E. EaD e a convergência digital. Disponível em: http://www2. abed. org.br/visualizaDocumento.asp?Documento_ID=131 Acesso em 25 fev. 2009.

RODRIGUES, Cleide Aparecida Faria \& SCHMIDT, Leide Mara. Introdução à Educação a Distância. Ponta Grossa: UEPG/ NUTEAD, 2010.

www.capes.br/ead

www.nutead.org

www.uepg.br/prograd

Recebido em: 12/09/2013

Aprovado em: 30/09/2013 